\title{
Aníbal Quijano, una presencia inspiradora ${ }^{1}$
}

\author{
Narda Henríquez ${ }^{2}$
}

En mayo, hace dos años, partió Aníbal Quijano. Desde entonces su presencia cobra renovada fuerza inspiradora. Colegas, académicos, amigos en el país y el extranjero han escrito recordando sus reflexiones, trayectoria académica, el brillo de su palabra, la vitalidad del quechua hablante que cantaba huainos y zambas, el inquisidor de siempre y su heterodoxo compromiso político.

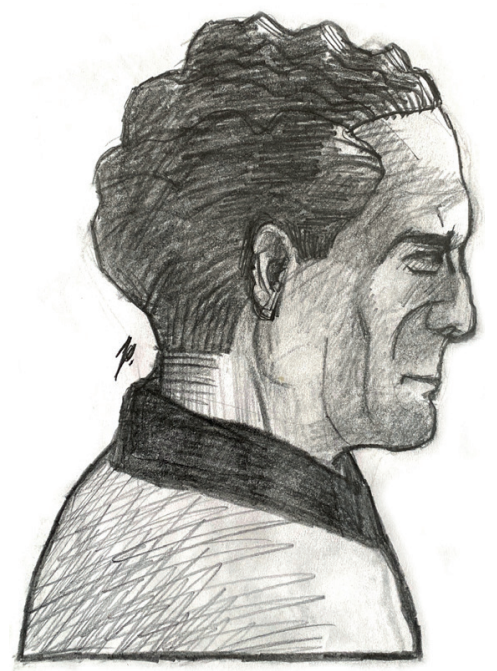

Retrato. Dibujo a lápiz de Piero Quijano Pimentel (2020).

\footnotetext{
1 Homenaje a Aníbal Quijano a dos años de su partida. Incluimos una semblanza y la transcripción de los textos de un taller titulado "Colonialidad del poder», realizado los días 14, 15 y 16 de junio de 2012 en la Pontificia Universidad Católica del Perú (PUCP), y organizado por el Grupo de Investigación sobre Conflictos y Desigualdades (GICO), coordinado por Narda Henríquez, con el auspicio de la Maestría en Sociología y el Departamento de Ciencias Sociales.

2 Profesora principal del Departamento de Ciencias Sociales, sección Sociología, PUCP. Correo electrónico: nhenriq@pucp.pe
} 
Aníbal sigue entre nosotros, desde su labor permanente para hurgar en la historia sobre los resquicios y subterfugios del poder, las tensiones y conflictos que aquejan a la existencia social de la especie humana y las tribulaciones de sujetos que labran sus caminos y sus sueños, sobre el modo de pensar lo cholo y lo indígena, en las reflexiones sobre el pasado y el futuro del Perú y América Latina.

Una presencia inspiradora de la que dan testimonio las páginas del texto que entregamos. Se trata de un taller sobre la colonialidad del poder que tuvo lugar en la PUCP en 2012, cuando Aníbal dialogó con investigadores y estudiantes. El texto que ahora ofrecemos es posible gracias a la diligente labor de un grupo de estudiantes, ahora egresados, liderados por Julio Villa e integrado por Luis Rondán, Adolfo Palacios y Vilma Zavaleta, que editaron y transcribieron las sesiones. Agradecemos también la colaboración del profesor Guillermo Rochabrún en la revisión del texto.

Los planteamientos de Quijano sobre la colonialidad del poder y su búsqueda persistente de nuevos horizontes utópicos y sentidos a la experiencia humana marcan un giro en el pensamiento crítico latinoamericano y en los modos de producción del conocimiento a nivel mundial. Es de esperar que sus trabajos sobre lo cholo, la marginalidad y la dependencia, desde un enfoque histórico estructural, puedan ser estímulos para repensar[nos] hoy a la luz de cambios locales y globales.

\section{Anduvo por el mundo, desde Yanama}

Aníbal compartió aulas con niños quechua hablantes en la escuelita donde su padre enseñaba. Muy joven conoce a Carmen Pimentel, su compañera de siempre, ambos caminaron de la mano enamorados de la vida. Anduvo por el mundo, desde Yanama, su pueblo natal en Ancash. Santiago, Ciudad de México, San Juan de Puerto Rico y Nueva York cuentan entre los lugares queridos donde enseñó y compartió con amigos la vida política e intelectual de la época. También estuvo en Venezuela, Ecuador, Brasil, Francia, Finlandia y Alemania, y fue testigo de la caída del muro de Berlín.

Desplegó sus inquietudes y conocimientos como profesor universitario en La Cantuta, la Universidad Agraria y la Universidad Nacional Mayor de San Marcos hasta 1995, cuando renuncia por la intervención fujimorista en el campus. Quienes lo conocimos en las aulas sanmarquinas recordamos sus clases a fines de los sesenta, en el curso sobre estratificación y clases sociales; los textos a mimeógrafo sobre la marginalidad, la clase obrera; los planteamientos sobre la dependencia y el imperialismo. Otras generaciones siguieron sus clases en los ochenta, y compartieron sus lecturas marxistas y mariateguistas en debate con Sendero.

En los setenta, Aníbal Quijano formó parte de un circuito de intelectuales que fueron testigos de los tiempos álgidos en el Chile de Allende: A. Gunder Frank, Mauro Marini, T. dos Santos. F. H. Cardoso, Enzo Faletto, entre otros, destacados investigadores de FLACSO y de CEPAL. Deportado durante el gobierno de Velasco, 
vivió exiliado en México, y a su regreso fundó y dirigió la revista Sociedad y Política, donde tuvo estrechos colaboradores como César Germaná y Felipe Portocarrero. En esos años promovió también círculos de estudio sobre el marxismo, y retomó una nueva etapa de actividad política ${ }^{3}$.

En los noventa, Aníbal siguió prodigándose en las aulas universitarias en el país y el extranjero, participando en agudos debates sobre el sistema mundo, el capitalismo y la colonialidad del poder. Debemos mencionar los diálogos y seminarios, entre 1998 y 1999, con Immanuel Wallerstein y E. Dussel en el Centro F. Braudel de la Universidad de Binghamton (Nueva York) y en la Universidad de Duke (Carolina del Norte) con W. Mignolo, C. Walsh, E. Lander. En esos años se configura como un referente en el pensamiento crítico conocido como grupo «modernidad/ colonialidad», que se nutrió del análisis y planteamientos conceptuales que Aníbal venía trabajando años atrás ${ }^{4}$. Participó también en múltiples foros internacionales vinculados a la Unesco, ISA, CLACSO, ALAS, y se involucró entusiastamente en el Foro Social Mundial desde su primera reunión en Porto Alegre (2001), donde convergen activistas y líderes de movimientos sociales, intelectuales y representantes de la sociedad civil.

Las reflexiones teóricas y la indagación sobre la práctica política eran parte de las mismas inquietudes presentes en sus artículos: el movimento obrero, el movimento campesino e indígena y el marxismo, como expresión de sus continuas aspiraciones de cambio social. Esto también se expresa en el entusiasmo inicial y pronta desilusión respecto de la descolonización del Estado durante el gobierno de Evo. Sus escritos sobre la colonialidad del poder ponen el acento en otras formas de existencia, la necesidad de las múltiples luchas y de otros mundos posibles. Así, a pesar de referirse en varias ocasiones a los «fracasos» que experimentaba la región, animaba de muchas maneras el pensamiento contrahegemónico y las expectativas por un futuro diferente, refiriéndose a la emergencia de imaginarios anticapitalistas ${ }^{5}$ y a las propuestas del bien vivir.

\footnotetext{
3 Sobre sus ańos de estudiante en la Universidad de San Marcos y una primera etapa de actividad política ver Valladares, 2019. En su juventud, Quijano fundó el Movimiento Revolucionario Socialista (MRS), y desplegó un activo vínculo con la Comunidad Autogestionaria de Villa El Salvador (CUAVES) y con líderes sociales como Apolinario Rojas. Fue un referente para jóvenes activistas como R. Espinoza, con quien tuvo una duradera amistad. Aunque sus escritos políticos son poco conocidos, participó activamente en la izquierda de la época.

4 C. Walsh se refiere a la reunión en Duke (1999) como un momento de «reflexión colectiva» que da lugar al grupo. Ver al respecto "Carta a Aníbal Quijano", escrita y leída por ella en el homenaje que organizaron la Universidad de San Marcos y la Universidad Ricardo Palma al año de su partida, el 8 de mayo de 2019.

5 Entrevista de Ivonne Trías a Aníbal Quijano, publicada originalmente en Brecha de Uruguay, titulada «Un nuevo imaginario anticapitalista». https://avanzadanacional.es.tl/Anibal-Quijano.htm
} 
Para comienzos de este siglo sus escritos e ideas eran conocidos y reconocidos internacionalmente, lo que no ocurría necesariamente en el Perú, en parte por su obra dispersa —aunque publicada en revistas internacionales y en varios idiomas-pero también por su distancia crítica de circuitos políticos nacionales. Dos acontecimientos son claves en la última década para un nuevo momento de diálogo con Aníbal Quijano. Por un lado, la publicación de la antología de sus principales trabajos, preparada por Danilo de Asís Clímaco y publicada por CLACSO en 2014 y, por otro, la conducción de la cátedra «América Latina y la colonialidad del poder», que la Universidad Ricardo Palma creó en $2010^{6}$. Estos acontecimientos, valiosos en sí mismos, brindan a Aníbal la oportunidad de relacionarse con las nuevas generaciones a partir de la difusión de sus obras y de establecer, como parte de las actividades de la cátedra, una plataforma de debate e intercambio con intelectuales peruanos y latinoamericanos, entre los cuales se contaban Rita Segato, Raquel Sosa, Ángel Quintero y Teivo Teivainen. En los últimos años, la voz y el talante de Aníbal nos llegaba también vía las redes virtuales, en eventos y homenajes en diversas universidades en el país y en el extranjero ${ }^{7}$.

Poco había hecho la academia peruana por difundir sus obras y acogerlo en sus aulas en esos años; sin duda teníamos una deuda con Aníbal Quijano, lo que señalé cuando me correspondió estar entre quienes presentaron el libro de CLACSO en Lima en 2014. Sin duda, la excepción fue la labor constante de un núcleo de profesores en San Marcos: César Germaná, Julio Mejía, Carolina Ortiz, algunos de los cuales luego lo acompañarían en la cátedra en la Universidad Ricardo Palma ${ }^{8}$. Al respecto, Gonzalo Portocarrero 9 ha seńalado que su influencia perdura y se aquilatará con los años, no solo en la academia sino también en el sentido común.

El maestro Quijano recibió reconocimientos en muchas universidades y su influencia entre los jóvenes traspasó las fronteras latinoamericanas. En medio de los reconocimientos y homenajes, no dejó la charla y el debate apasionado, en ámbitos locales y cotidianos, sobre política, un último libro que llegó a sus manos o los acontecimientos mundiales. Trejo y de buen talante, lo vimos varias veces en Villa El Salvador, donde estuvo vinculado a círculos políticos antes, y ahora colaboraba en

\footnotetext{
6 La cátedra se propone como un referente institucional académico que «permita la elaboración y profundización sistemática de las bases teóricas que América Latina está proponiendo en el debate mundial». Ver www.urp.edu.pe/catedras

7 Entre ellos la conferencia «La colonialidad/descolonialidad del poder», en el homenaje que promovimos con Jo Marie Burt, desde la sección Perú de LASA en Puerto Rico (2015), en colaboración con CLACSO. Ver https://www.youtube.com/watch?v=UhQU4HtGDpY

8 En torno a la cátedra estarán César Germaná — que tuvo una continua y cercana vinculación con Aníbal Quijano desde la década de 1970—, José Martínez, Eduardo Arroyo, Jaime Ríos y Jaime Coronado.

9 Gonzalo Portocarrero, quien también nos dejó a los pocos meses, escribió que su influencia también se observa en el modo en el cual términos como colonialidad ingresan al sentido común (2018).
} 
seminarios y talleres sobre el racismo, la salud y los derechos humanos, la economía solidaria, etcétera ${ }^{10}$. Así lo vimos también en tertulias amicales, que durante muchos años se volvieron entrañables rituales, cuando la lucidez aumentaba con las horas, disfrutaba los amigos y los amigos lo disfrutábamos en animados y a veces acalorados diálogos y siempre con música y compartiendo afectos con Carmencita y con Orlando Plaza, Beatriz Cobián, Inés García, Gerardo Chu, Roberto Wangeman, Luis Herrrera, Ernesto Choy, Marisol Vega, Luis Peirano, Rolando Ames ${ }^{11}$. Tenía una vívida memoria de los encuentros ocasionales e intensos con Gustavo Gutiérrez, o aquellos cultivados en continuidad como con Abelardo Oquendo, Mirko Lauer, Carlos Araníbar y los amigos de siempre como Rodrigo Montoya y Heraclio Bonilla.

\section{El poder, la estructura de sentir y que las ideas no sean cárceles}

Como se podrá observar en las páginas que siguen, Quijano explica la complejidad y dinámica de la construcción del conocimiento cuando se refiere a los fundamentos de sus planteamientos sobre colonialidad del poder, y convoca a llevar a cabo investigaciones para profundizar las rutas que él ha venido trazando. Quijano se refiere a la colonialidad del poder como el patrón de poder colonial que persiste y que está en diversos ámbitos de nuestra existencia: sexo, trabajo, subjetividad, comunicación, autoridad colectiva, arte-juego-rito, naturaleza. Explica que si bien ańos atrás había identificado cuatro ámbitos ahora, se refiere a siete, los mismos que son interdependientes y que podrían ser más; deja abierto, por ejemplo, que se podría incluir a la religión.

Este patrón corresponde a un "modo específico de relaciones sociales», mecanismos de dominación que se reconstituyen en torno lo que denominamos «raza», que surge como novedad histórica en el período del descubrimiento-conquista. El proceso de descubrimiento-conquista es el momento clave en que los conquistadores «indigenizan» a las poblaciones colonizadas de América primero y luego a la mayoría del resto del mundo, inventando la palabra «indio» y así racializando y homogenizando a los otros. A pesar de las historias heterogéneas y procesos diferentes por los que transcurrieron estas poblaciones, dice Quijano que la crisis de la colonialidad da lugar a un emergente «movimiento de la sociedad» que podría llevar a la «des/colonialidad global del poder, esto es a otra existencia social, liberada de dominación /explotación /violencia» (2014a, p. 31).

Rita Segato (2014) afirma que la contribución teórica de Quijano introduce un giro en el pensamiento latinoamericano y mundial, y agrega que «a pesar de ser

\footnotetext{
10 En el marco de las actividades de la ONG CECOSAM, de apoyo psicosocial, dirigida por la esposa de Aníbal, Carmen Pimentel, junto a un equipo de jóvenes psicólogos.

11 Estas tertulias eran acompañadas de la amistad y la música de Carlos Saldarriaga, y en los últimos años también con Danilo Quijano y el arpa y la voz de Pedro Pablo Ccopa.
} 
concebida a partir de una mirada localizada en el paisaje latinoamericano y aunque reconfigura el discurso de la historia de las relaciones de América en la estructura de poder mundial, esta perspectiva teórica no solo se refiere a América Latina sino al conjunto del poder globalmente hegemónico» (p. 36). Asimismo, explica que «el giro "decolonial" es un giro epistémico que emerge de una nueva relectura del pasado que reconfigura el presente y que tiene como proyecto la producción democrática de una sociedad democrática» (p. 59).

La contundencia y densidad de sus proposiciones sobe la colonialidad tienen creciente aunque tardía influencia en las nuevas generaciones del Perú contemporáneo; sus textos se vuelven de lectura imprescindible en medios académicos y circuitos de activistas. Como en el caso de José Carlos Mariátegui, los textos de Aníbal Quijano pueden tener varias lecturas por la fuerza analítica e interpeladora del conocimiento y de nuestras propias subjetividades y la capacidad de enunciación como parte de construcciones discursivas de denuncia y de corrientes contrahegemónicas ${ }^{12}$.

Hay que advertir, como C. Walsh en su «Carta a Aníbal Quijano» (2019), que para Quijano la colonialidad del poder no era un concepto para posicionar como paradigma sino una "herramienta analítica», concepto relevante para la academia global y para la práctica política de colectivos y movimientos en su búsqueda por otros modelos de vida. También hay que tener presente, como él alguna vez lo hizo, que el conocimiento se nutre de procesos teóricos que se alimentan de la experiencia y de la práctica y que "las ideas son cárceles de larga duración» en las que no necesariamente tenemos que permanecer ${ }^{13}$. De este modo, desde un enfoque crítico, de trabajo teórico y metodológico creativo, Aníbal nos desafía y está presente en un circuito amplio de académicos y jóvenes investigadores así como de líderes y activistas.

El anclaje local de Quijano está, desde mi punto de vista, tanto en el núcleo de sus planteamientos recientes sobre la colonialidad como en sus previos escritos sobre la marginalidad, lo cholo y la heterogeneidad estructural. Y también en las referencias a Mariátegui, donde anidan y coexisten tiempos, y en las lógicas estructurales heterogéneas enunciadas en sus ensayos sobre el problema del indio, la descentralización, y el reconocimiento de existencias plurales que se entrelazan y conviven en la complejidad de lo que él denomina el «nudo arguediano». Por tanto, es un anclaje desde el Perú y América Latina para el mundo.

12 Las propuestas discursivas del bien vivir no tienen en el Perú el arraigo que tuvieron en otros países. Sin embargo, están en el debate político y entre sectores de la sociedad civil que adhieren a posturas decoloniales. Rocío Silva Santisteban, académica, feminista y actual parlamentaria, afirmó que «el feminismo solo puede ser decolonial», en su intervención en San Marcos en el primer aniversario del fallecimiento de Aníbal, en mayo de 2019.

13 Aníbal Quijano, «Las ideas son cárceles de larga duración, pero no es indispensable que permanezcamos todo el tiempo en esas cárceles». CLACSO, XIII Asamblea General, Montevideo, 1985. 
Al respecto, Danilo de Asís Clímaco ha señalado que con la teoría de la colonialidad Aníbal Quijano toma distancia del pensamiento liberal y de las élites en América Latina, contribuyendo a repensar el lugar de América Latina en la producción de conocimiento. Por su parte, Guillermo Rochabrún (2018) ha subrayado que entender la especificidad de América Latina ha sido para Aníbal una tarea permanente.

Desde mis lecturas, podría decir que la marginalidad y la economía popular son a la acumulación capitalista lo que la colonialidad es a la modernidad europea homogenizante. Ese proceso abre camino a nuevas estructuras de sentir, de saber, de vivir. Si antes tuvieron centralidad el trabajo y la clase obrera, ahora lo tienen la colonialidad del poder y la raza, pero en este marco Quijano nos habla de múltiples dimensiones interconectadas y, aunque no trabaja todas ellas a fondo, las considera igualmente relevantes. He hurgado en este anclaje local de Aníbal y sus repercusiones globales, pero sobre todo me siento inclinada a indagar en las pistas que nos ofrece sobre el Perú. Las continuidades entre lo cholo y lo indio, la marginalidad y la colonialidad, la heterogeneidad y el patrón de poder renuevan mi interés sobre dos dimensiones, los cambios en las formas de autoridad, las mediaciones institucionales y las relaciones de poder, y sobre los cambios en las subjetividades.

Sus estudios sobre lo cholo y lo indígena no solo colocan las cuestiones culturales en la constitución plural de la sociedad, explorando sus demandas y proyectos a nivel colectivo, sino que son también una atenta y comprometida mirada a las estructuras del sentir de las personas, sus subjetividades, sus formas de vida y de existir; en ese sentido confluyen con las dimensiones de género, aunque no lo trabaje de ese modo.

\section{Beber de las fuentes. Inquisidor, maestro, hermano grande}

Aníbal representa hoy un clásico en el pensamiento social peruano y es un reconocido representante del pensamiento crítico latinoamericano. Un clásico es aquel que nos traza el camino para hacer preguntas relevantes en las ciencias sociales, en nuestra propia existencia.

Beber de las fuentes primarias y poner en diálogo el pasado, presente y futuro estaría también en sus lecturas entusiastas de la nueva edición de la obra de Guamán Poma de Ayala, preparada por el historiador Carlos Araníbar (2015) y a cuya relectura estaba dedicado en los últimos ańos de su vida. Quijano se refiere a los textos de Guamán Poma como la primera gran revolución de la palabra y una protesta que a la vez podría preconfigurar el futuro, al imaginarse una sociedad buena y justa ${ }^{14}$.

Nutrirse también del diálogo y del debate, y ser un permanente y a veces incómodo inquisidor era para él un mandato. Así también lo recuerdo en su diálogo con

\footnotetext{
14 Aníbal fue uno de los comentaristas en la presentación de esta edición, de la Biblioteca Nacional del Perú, en diciembre de 2015. Ver https://www.youtube.com/watch?v=SJL7zpmkzq8
} 
las nuevas generaciones de estudiantes universitarios en su alocución en la apertura del año académico en el auditorio de Ciencias Sociales en San Marcos (2017), tal vez su última presentación pública, retando a los presentes —estudiantes, profesores, amigos-: "Qué piensan ustedes [...] cuáles son los desafíos hoy, qué cuestiones hay que debatir [...] de repente es tiempo de volver a las estructuras [...] y esas cuestiones ¿cómo piensan resolverlas?» Así no solo dejó cuestiones abiertas, sino que sigue abierto el desafío que nos plantea a retomar y recrear cuestiones.

Agradezco a Aníbal, el maestro, que quiso dejar su palabra entre nosotros y que estuvo en las aulas del Fundo Pando en varias oportunidades durante la última década $(2007,2011,2012,2013,2017)^{15}$, en conversatorios con profesores y estudiantes, en talleres y conferencias. Destacamos entre ellas, la participación de estudiantes e investigadores PUCP al lado de estudiantes de San Marcos y de las universidades de Huamanga y la Amazonía en 2011; la presencia de colegas de la región y del extranjero en un breve homenaje en 2017 en el marco de los cien años de la PUCP.

Aníbal, ciudadano del mundo, aldeano y cosmopolita, hermano grande, te saludo como siempre, y te cuento que he seguido abrazando a Carmencita, a Piero y a Rodrigo, tus hijos, hasta que nos sorprendió la pandemia. Ahora alimentamos los afectos y consolamos nuestros dolores a distancia. En medio del confinamiento, agradezco a Piero el arte y los trazos que nos ofrece para acompañar estas páginas. Antes como ahora, tu presencia desbordante de energía y alegría renueva nuestra esperanza. Espero estés en las alturas con los Apus, bailando cual diablillo feliz. Aníbal, hermano grande, seguiremos compartiendo relecturas, en convergencias y divergencias, que de eso se nutrió nuestra amistad y nuestros diálogos.

\section{REFERENCIAS}

Portocarrero, G. (2018). Aníbal Quijano y su aporte. El Comercio, 6 de junio de 2018.

Quijano, A. (2014a). Des/colonialidad y Bien Vivir. Un nuevo debate en América Latina. Lima: Universidad Ricardo Palma.

Quijano, A. (2014b). Cuestiones y horizontes. De la dependencia histórico-estructural a la colonialidad / descolonialidad del poder. En A. Quijano, Antología general, selección y prólogo a cargo de Danilo de Asís Clímaco. Buenos Aires: CLACSO.

Rochabrún, G. (2018). Mi deuda impagable con Aníbal Quijano. Ideele, 280.

Segato, R. (2014). Aníbal Quijano y la perspectiva de la colonialidad del poder. En A. Quijano, Antología general (pp. 35-72). Buenos Aires: CLACSO

Valladares, M. (2019). Aníbal Quijano, orígenes de sus luchas contra el poder. Investigaciones Sociales, 22(40), 385-393.

15 Con el apoyo del Departamento de Ciencias Sociales y la Maestría en Sociología y el auspicio de la DAPE, el Doctorado en Sociología y el Grupo de Investigación en Conflictos y Desigualdades (GICO). 


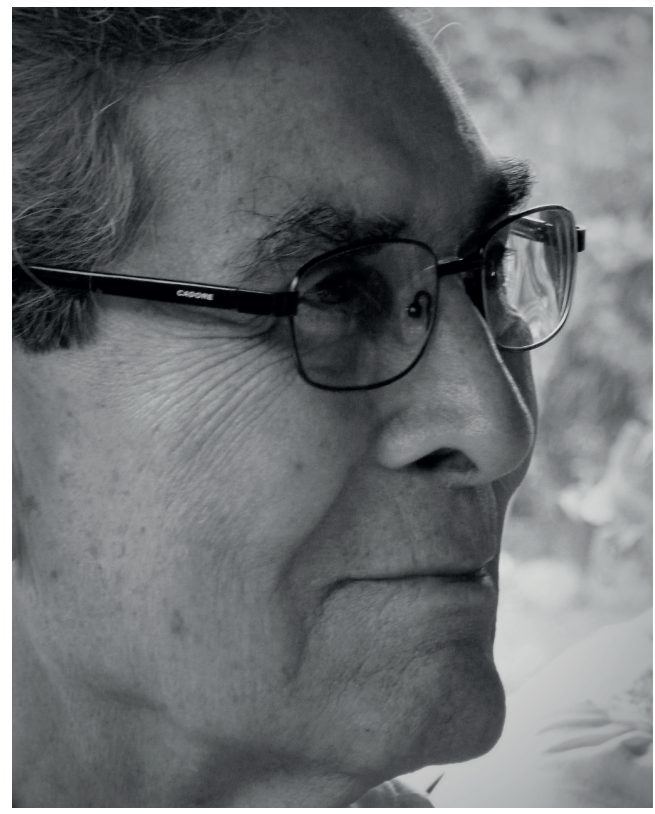

Fotografia de Roberto Wangeman (2014).

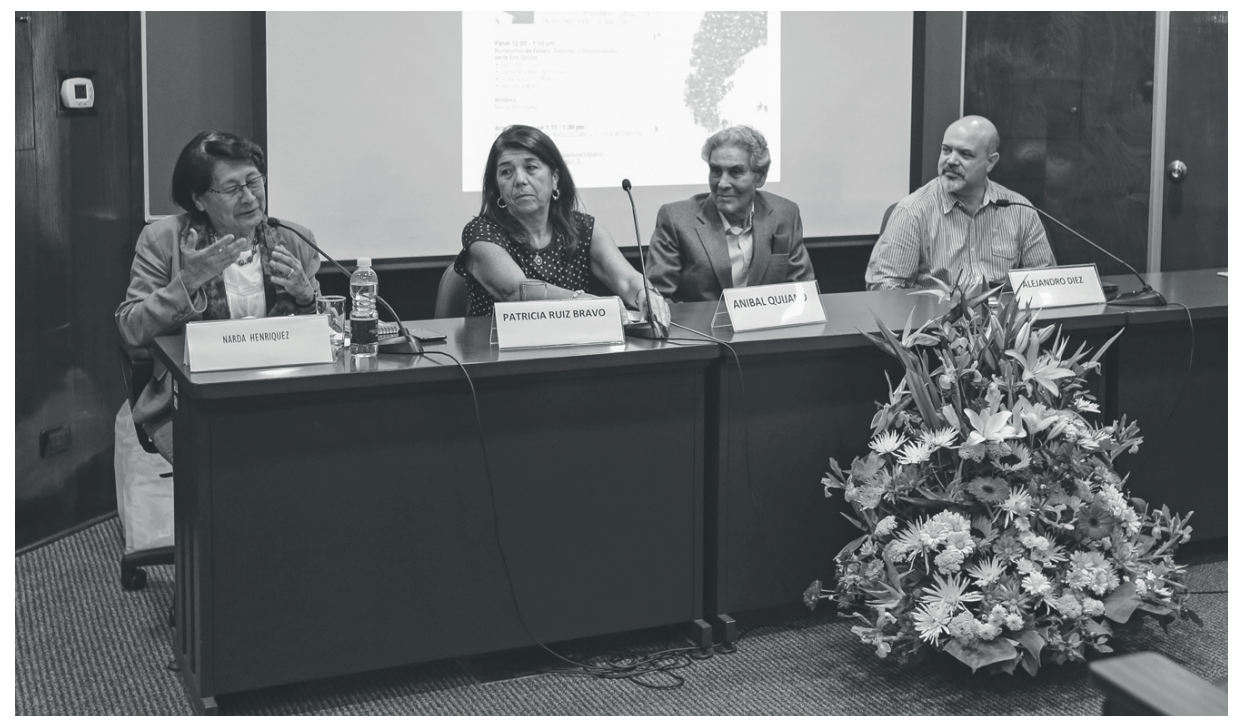

Homenaje de Ciencias Sociales a Aníbal Quijano, PUCP, 4 de mayo 2017. Foto: PuntoEdu. 


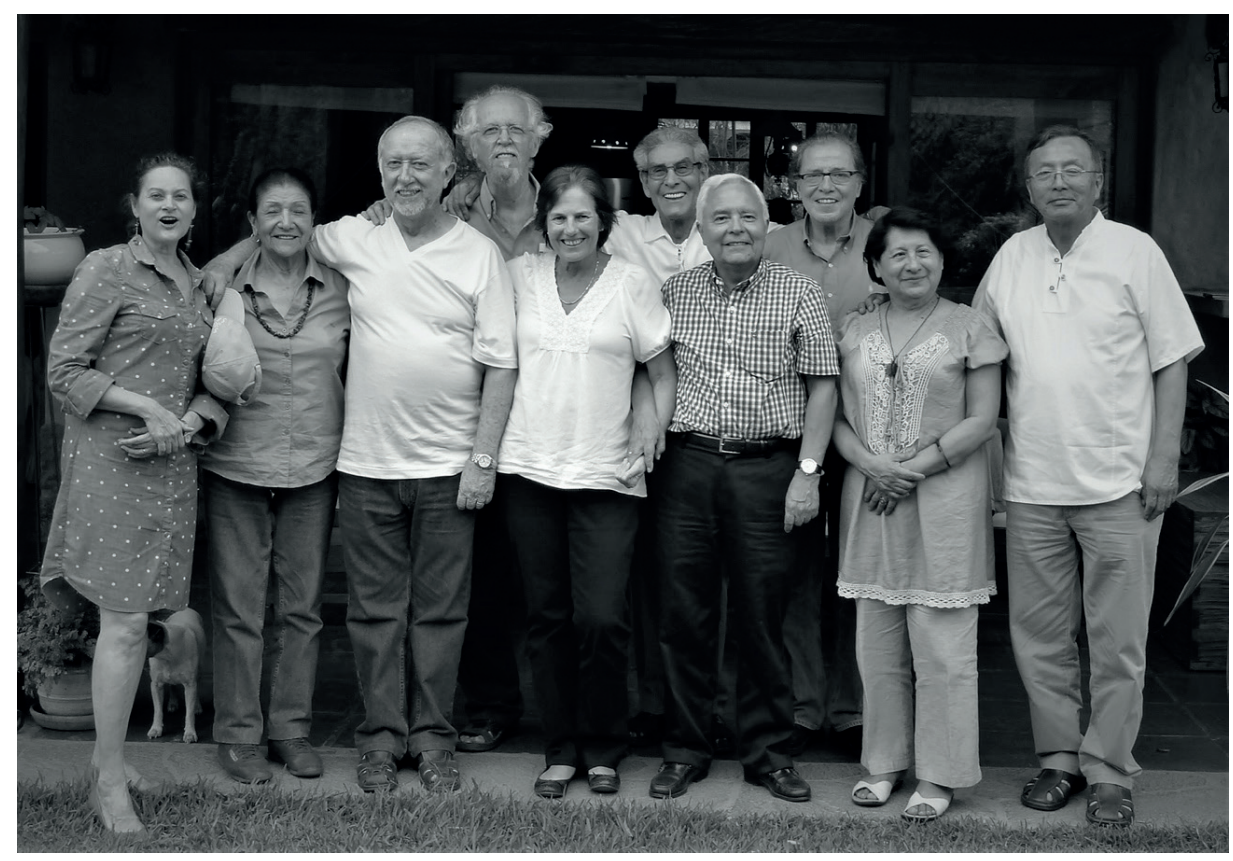

De izquierda a derecha: Bertha Pancorvo, Carmen Pimentel, Lucho Peirano, Roberto Wangeman, Beatriz Cobián, Aníbal Quijano, Orlando Plaza, Luis Herrera, Narda Henríquez, Ernesto Choy. Fotografía de Roberto Wangeman (2014). 